\title{
Use of double wire-guided technique and trans- pancreatic papillary septotomy in difficult ERCP: 4-year experience
}

Authors

Institutions
Connie Huang' ${ }^{1}$ Jonathan Kung ${ }^{1}$, Yong Liu' ${ }^{1}$, Audrey Tse ${ }^{1}$, Anuj Datta ${ }^{1,2}$, Inder Singh ${ }^{1}$, Viktor E. Eysselein ${ }^{1,2}$, Sofiya Reicher ${ }^{1,2}$

${ }^{1}$ Harbor-UCLA Medical Center, Department of Medicine, Division of Gastroenterology \& Hepatology, Torrance, CA, USA ${ }^{2}$ David Geffen School of Medicine at UCLA, Division of Digestive Diseases, Los Angeles, CA, USA submitted 25. January 2016 accepted after revision 2. August 2016

\section{Bibliography}

Dol http://dx.doi.org/ 10.1055/s-0042-115407 Published online: 21.9.2016 Endoscopy International Open 2016; 04: E1107-E1110 (c) Georg Thieme Verlag KG Stuttgart · New York E-ISSN 2196-9736

\section{Corresponding author} Sofiya Reicher, MD MFI Professional Building 21840 South Normandie Ave Suite 450

Torrance

CA 90502

USA

Fax: +1-310-212-7837 sreicher@sbcglobal.net
Background and aims: Post-ERCP complications increase with repeated attempts at cannulation. We evaluated several advanced biliary cannulation techniques applied when the standard approach fails.

Methods: In total, 1873 consecutive patients underwent ERCP at our institution during the period 2010-2014. Guidewire-assisted (GA) cannulation with no contrast injection until deep biliary cannulation was considered the standard technique. Advanced techniques used were double wire-guided (DWG) cannulation, transpancreatic papillary septotomy (TPS), and needle-knife sphincterotomy (NKS). When GA cannulation failed, DWG cannulation was usually attempted first if the pancreatic duct (PD) wire was in place; if that failed, TPS or NKS was performed. Alternatively, TPS or NKS were performed alone. A prophylactic pancreatic stent was placed with repeated PD cannulation or PD contrast injection. During the last 2 years of review, indomethacin

\section{Introduction}

\section{$\nabla$}

The success rate for biliary cannulation using the standard guidewire-assisted (GA) technique is approximately $90 \%$ [1]. In up to $10 \%$ of all cases, the standard technique is unsuccessful, and difficult biliary cannulation is encountered [2,3]. Difficult or failed bile duct cannulation can lead to increased morbidity and mortality [1]; in particular, post-endoscopic retrograde cholangiopancreatography (ERCP) pancreatitis is associated with repeated attempts at cannulation. When the standard technique fails, commonly used advanced endoscopic techniques to gain bile duct access include double wire-guided (DWG) cannulation, and the precut techniques of needle-knife sphincterotomy (NKS) and transpancreatic papillary septotomy (TPS) [4].

Past studies evaluating the use of advanced techniques and their associated complications have suppositories were given post-procedure to all patients who underwent advanced techniques. Results: The overall biliary cannulation success rate was $97 \%$ (1823/1873). Advanced techniques were used in $12 \%$ of ERCPs (230/1873), with $87 \%$ (200/230) success rate. DWG was used alone or in combination with other techniques in 58\% (134/230) of advanced cases, with 68\% (91/134) success rate. Biliary cannulation was achieved in 96\% (91/95) of procedures when DWG was used alone, 76\% (26/34) with TPS alone, 80\% (37/46) for NKS alone, and $84 \%(46 / 55)$ with multiple techniques. The overall rate of post-ERCP pancreatitis was $0.4 \%$, with all patients treated conservatively.

Conclusion: In our experience at an urban tertiary care center, use of advanced techniques in difficult ERCP improved the overall success rate of biliary cannulation after standard technique failure without a significant increase in complication rate.

produced conflicting results [5]. Recent studies indicate that DWG, TPS, and NKS improve cannulation success rates without a significant increase in post-ERCP complications [6-13]; however, there are limited data on the use of these techniques and how they improve clinical outcomes. Here, we report our experience with the advanced biliary cannulation techniques, used alone or in combination when the standard GA approach fails, and their respective success/complication rates.

\section{Methods \\ $\nabla$}

We retrospectively reviewed 1873 consecutive patients who underwent ERCP at our institution. The endoscopic database was queried for all ERCP procedures performed between May 2010 and September 2014. Medical records were eval- 
uated for patient demographics including age, gender, race, and procedure indication. Procedure reports were evaluated for techniques used and bile duct cannulation success. Complications were assessed by detailed examination of electronic medical records, laboratory and imaging data. All procedures were performed by three endoscopists (VE, SR, IS) with extensive experience in ERCP.

The standard technique was defined as GA cannulation with contrast injection only after deep biliary cannulation is achieved. Difficult biliary cannulation was defined as more than five contacts with the papilla during the attempt to cannulate, more than 5 minutes attempting to cannulate, or more than one unintentional pancreatic duct (PD) cannulation [4]. The advanced biliary cannulation techniques used were DWG, TPS, and NKS. In DWG, the bile duct is cannulated alongside a wire inserted in the PD, using the PD wire as a guide. Routinely, DWG was attempted after one unintended PD cannulation, with the PD wire left in place, thus avoiding repeated PD cannulations. In TPS, a partial septotomy is performed after the sphincterotome is introduced into the common channel of the papilla. GA cannulation is then reattempted. NKS is a precut technique in which a catheter with a thin wire extending beyond the tip of a freehand needle-knife is inserted into the papilla to make a small incision, followed by GA cannulation. When difficult biliary cannulation was encountered (i.e., standard technique failed) DWG cannulation was usually attempted first if the PD wire was in place. If DWG did not succeed, TPS or NKS was then performed; alternatively, TPS or NKS was used alone. Multiple techniques were often used in the same procedure. In general, if DWG failed and access to the common channel was available, TPS was performed and NKS was applied as a rescue technique in patients where TPS failed. This was the approach we commonly used throughout the 4-year period, although there was no predetermined/standardized algorithm and the choice of advanced techniques was left to the discretion of the performing endoscopist based on the individual factors of each case.

In the case of repeated PD cannulation or PD contrast injection, a prophylactic pancreatic stent was placed. During the last 2 years of review, indomethacin suppositories were given immediately post-procedure to all patients who had undergone advanced cannulation techniques to reduce the risk of pancreatitis.

\section{Results \\ $\nabla$}

In total, 1873 consecutive patients (average age 49; 69\% females) underwent ERCP at our institution over the 4-year period, and the advanced techniques were employed in $12 \%$ (230/1873) of cases. Table 1 shows the demographic data for the patients who underwent biliary cannulation using advanced techniques. The most common indication for ERCP requiring advanced techniques was jaundice secondary to stone disease or malignancy; $90 \%$ (207/230) of the ERCPs requiring advanced techniques were performed on native papillae.

\section{Procedure outcomes}

The overall biliary cannulation success rate at the 1 st procedural attempt was $97 \%(1823 / 1873)$. Fig. 1 a shows the procedure outcomes for all patients utilizing DWG, TPS, and/or NKS techniques. The biliary cannulation success rate of all procedures with advanced techniques was $87 \%$ (200/230). DWG was used alone or in combination with other techniques in $58 \%(134 / 230)$
Table 1 Patient demographics for endoscopic retrograde cholangiopancreatographies (ERCPs) requiring advanced techniques.

\begin{tabular}{|l|c|}
\hline Parameter & n (\%) \\
\hline Procedures with advanced techniques & 230 \\
\hline Age, years & 49 \\
\hline Sex & $72(31 \%)$ \\
\hline Male & $158(69 \%)$ \\
\hline Female & 142 \\
\hline Race & 53 \\
\hline Hispanic & 18 \\
\hline White & 16 \\
\hline Black & 1 \\
\hline Asian & \\
\hline Unknown & $142(62 \%)$ \\
\hline Indications & $19(8 \%)$ \\
\hline Choledocholithiasis & $69(30 \%)$ \\
\hline Pancreatic mass & \\
\hline Other &
\end{tabular}

of patients. DWG was successful in 68\% (91/134). Biliary cannulation was achieved in 96\% (91/95) of patients when DWG was used alone; in four patients, the ERCP was aborted after DWG failure. In the remaining 39 of the 134 patients, TPS or NKS, or both, were performed after DWG failed ( $\nabla$ Fig. 1 b). TPS rescue after DWG failure was used in 26 out of the 39 patients, with biliary cannulation achieved in $96 \%(25 / 26)$. NKS rescue after DWG failure was used in four out of the 39 patients, with biliary cannulation in $100 \%(4 / 4)$. TPS and NKS in combination were used in nine patients, with a biliary cannulation rate of $44 \%(4 / 9)$ (ه Fig. 1 b).

TPS alone (i.e. without DWG) was used after GA cannulation failure in 34 of the 230 patients, with biliary cannulation achieved in $76 \%$ (26/34) of patients ( Fig. 1 a). NKS alone was used in 46 of the 230 patients, with biliary cannulation in $80 \%$ (37/46) of patients. Overall, multiple techniques were used in combination in 55 of the 230 patients, with $84 \%$ (46/55) biliary cannulation achieved. There was a trend towards increasing use of TPS technique over the 4-year period.

Of the 50 patients (out of the total 1873) who failed the 1 st procedural cannulation attempt and required repeat ERCP, 30 failed advanced techniques during the 1 st procedural attempt; $43 \%$ of those $(13 / 30)$ were successfully cannulated with standard technique on repeat procedure. Overall, 34\% (17/50) of repeat ERCPs had successful GA cannulation on repeat procedure ( $\bullet$ Fig. 1 a).

\section{Post-procedure complications}

The overall rate of post-ERCP pancreatitis was 0.4\% (7/1873); all cases were mild and managed conservatively without invasive procedures. Table 2 shows the post-procedure complications for patients who required advanced techniques. Post-ERCP pancreatitis occurred in $3 \%$ (7/230) of advanced cases, defined as new or worsened abdominal pain, prolongation of hospitalization for two or more days, and elevation of serum lipase or amylase greater than three times the upper limit of normal. Out of the seven cases of post-ERCP pancreatitis, there was one involving multiple techniques (DWG plus TPS). One case of micro-perforation occurred after NKS, where air was noted on cross sectional imaging. This was treated conservatively with antibiotic therapy and nasogastric tube suction. 


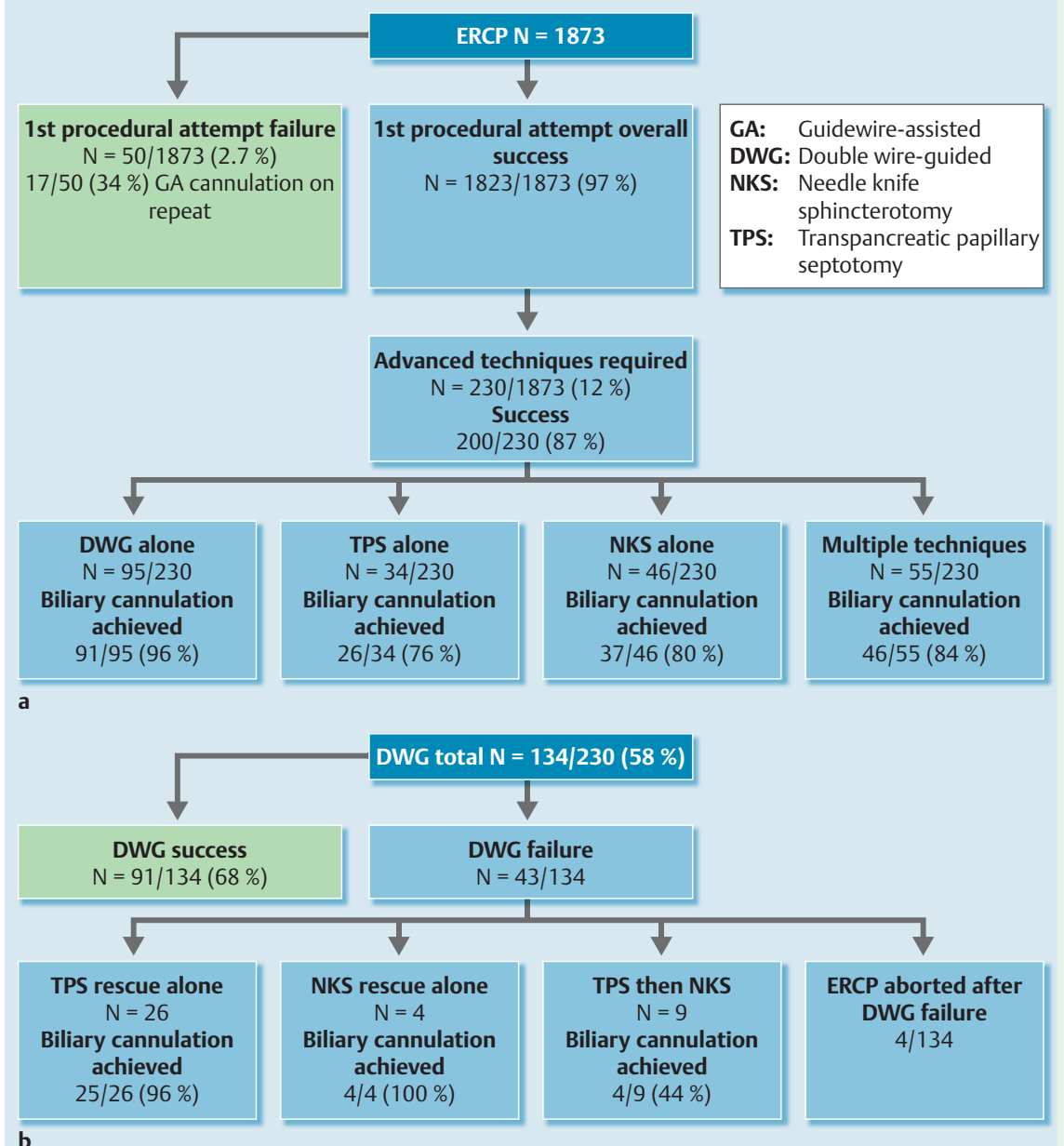

Fig. 1 a Procedure outcomes for endoscopic retrograde cholangiopancreatographies (ERCPs) requiring advanced techniques. $\mathbf{b}$ Double wireguided (DWG) technique outcomes.

\begin{tabular}{|c|c|c|c|c|c|}
\hline & DWG alone & TPS alone & NKS alone & DWG + TPS & $\begin{array}{l}\text { Complication rate for } \\
\text { advanced techniques (\%) }\end{array}$ \\
\hline Post-ERCP pancreatitis & 3 & 1 & 2 & 1 & $7 / 230(3 \%)^{1,2}$ \\
\hline Micro-perforation & 0 & 0 & 1 & 0 & $1 / 230(0.4 \%)^{2}$ \\
\hline Bleeding & 0 & 0 & 0 & 0 & 0 \\
\hline
\end{tabular}

Table 2 Post-procedure complications for endoscopic retrograde cholangiopancreatographies (ERCPs) requiring advanced techniques.

DWG, double wire-guided; NKS, needle-knife sphincterotomy; TPS, transpancreatic papillary septotomy.

${ }^{1}$ All pancreatitis cases mild.

2 Treated conservatively.

\section{Discussion}

$\nabla$

Selective biliary cannulation fails in approximately $10 \%$ of patients when the standard GA technique is used [1-3]. A difficult cannulation itself is associated with an increased risk for postERCP complications. Possible explanations for increased risk of post-ERCP pancreatitis include repeated manipulation causing mechanical damage or edema of the pancreatic sphincter, or excessive contrast injections to the pancreatic duct. Freeman et al. [14] reviewed 1963 ERCPs at 11 institutions in the United States and showed that the risk of pancreatitis after a difficult cannulation increased from $4.3 \%$ to $11.3 \%$ (compared with a standard GA cannulation). Several advanced techniques such as DWG, TPS, and NKS have been developed as rescue techniques when the standard approach fails. Some earlier studies suggested higher rates of post-ERCP pancreatitis associated with the advanced techniques, especially NKS and TPS. A meta-analysis [15] reported an increased risk of complications with cannulation time greater than 10 minutes, one or more deep PD wire passes, and
NKS. On the other hand, a recent study by Sasahira et al. [16] showed no difference in selective biliary cannulation rate or post-ERCP pancreatitis between multiple single-wire attempts and early DWG. More recent studies indicate that post-ERCP pancreatitis is associated with the number of cannulation attempts rather than directly with NKS and TPS [6,7].

Early use of advanced techniques is being increasingly recommended, as it may reduce the number of cannulation attempts. Lee et al. [17] conducted a prospective study of 711 patients with native papillae to evaluate the rates of success and complications with an algorithm in which sequential DWG and NKS were used when the standard GA technique failed. The results showed no difference in complication rates when compared to the standard technique. Our study also demonstrates a high success rate of first procedural biliary cannulation and low complication rates with these advanced techniques.

- Table 3 compares our complication rates using advanced techniques with those previously published $[7,8,11,16]$. In the study conducted by Wang et al. [8], the biliary cannulation rate using 
Table 3 Comparison of complication rates with advanced techniques in our study with literature data.

\begin{tabular}{|c|c|c|c|}
\hline & DWG alone & TPS alone & NKS alone \\
\hline \multicolumn{4}{|l|}{ Literature } \\
\hline \multirow[t]{2}{*}{ Success, \% } & $72[11]$ & $90[8]$ & $90.8[8]$ \\
\hline & $75[16]$ & $95.9[7]$ & $84.2[7]$ \\
\hline \multirow[t]{2}{*}{ Complication, \% } & $4[11]$ & $14.3[8]$ & $18.4[8]$ \\
\hline & $20[16]$ & $9.6[7]$ & $10.5[7]$ \\
\hline \multicolumn{4}{|l|}{ Our study } \\
\hline Success, \% & 68 & 76 & 80 \\
\hline Complication, $\% 1$ & 3.2 & 2.9 & 6.5 \\
\hline
\end{tabular}

DWG, double wire-guided; NKS, needle-knife sphincterotomy; TPS, transpancreatic papillary septotomy.

${ }^{1}$ For comparison, complication rates for each of the advanced techniques are shown.

TPS alone was $90 \%$ with a complication rate of $14.3 \%$; the biliary cannulation rate for NKS alone was $90.8 \%$ with a complication rate of $18.4 \%$. Zang et al. [7] reported biliary cannulation in $84.2 \%$ with $10.5 \%$ of patients experiencing complications using NKS. In our study, TPS alone had the lowest post-ERCP complication rate $(2.9 \%)$ among all advanced procedures used. The biliary cannulation rate for NKS alone in our study was $80 \%$, comparable to that reported by Zang et al. [7]. Similarly, the patients who underwent NKS alone had the highest post-ERCP complication rate (6.5\%). In a study conducted by Ito et al. [11], DWG was successful in $72 \%$ of patients, with an incidence of postERCP complications of $4 \%$. In our study, DWG had similar success $(68 \%)$ and complication $(3.2 \%)$ rates.

We report a large series of ERCP cases, with a significant percentage $(12 \%)$ requiring advanced techniques in difficult biliary cannulation. Given its retrospective nature, our study has a number of limitations. There was no predetermined/standardized algorithm, and the choice of advanced techniques was left to the discretion of the performing endoscopist based on the individual factors of each case. However, as described, we applied a common approach to difficult biliary cannulations. There is an inherent possibility of biases in a retrospective review; however, as stated in the Methods section, our study carefully examined all electronic medical records and detailed laboratory and imaging data in evaluating procedural success and complication rates.

Our experience at an urban tertiary care center indicates that the use of advanced techniques in difficult ERCP improves the overall success rate of biliary cannulation after standard technique failure without a significant increase in complication rate.

Competing interests: None

\section{References}

1 Freeman ML, Guda NM. ERCP cannulation: a review of reported techniques. Gastrointest Endosc 2005; 61: 112 - 125

2 Huibregste KKM. Endoscopic retrograde cholangiopancreatography, endoscopic sphincterotomy and endoscopic biliary and pancreatic drainage. In: Textbook of gastroenterology. Philadelphia, PA: Lippincott Williams \& Wilkins; 1995: 2590-2617

3 Bailey AA, Bourke MJ, Williams SJ et al. A prospective randomized trial of cannulation technique in ERCP: effects on technical success and post-ERCP pancreatitis. Endoscopy 2008; 40: 296-301

4 Testoni PA, Mariani A, Aabakken L et al. Papillary cannulation and sphincterotomy techniques at ERCP: European Society of Gastrointestinal Endoscopy (ESGE) Clinical Guideline. Endoscopy 2016; 48: 657683

5 Navaneethan $U$, Konjeti R, Venkatesh PG et al. Early precut sphincterotomy and the risk of endoscopic retrograde cholangiopancreatography related complications: An updated meta-analysis. World J Gastrointest Endosc 2014; 6: 200-208

6 Swan MP, Alexander S, Moss A et al. Needle knife sphincterotomy does not increase the risk of pancreatitis in patients with difficult biliary cannulation. Clin Gastroenterol Hepatol 2013; 11: 430-436

7 Zang J, Zhang C, Gao J. Guidewire-assisted transpancreatic sphincterotomy for difficult biliary cannulation: A prospective randomized controlled trial. Surg Laparosc Endosc Percutan Tech 2014; 24: 429-433

8 Wang $P$, Zhang W, Liu F et al. Success and complication rates of two precut techniques, transpancreatic sphincterotomy and needle-knife sphincterotomy for bile duct cannulation. J Gastrointest Surg 2010; 14: $697-704$

9 Kapetanos D, Kokozidis G, Christodoulou D et al. Case series of transpancreatic septotomy as precutting technique for difficult bile duct cannulation. Endoscopy 2007; 39: 802-806

10 Weber A, Roesch T, Pointner S et al. Transpancreatic precut sphincterotomy for cannulation of inaccessible common bile duct: a safe and successful technique. Pancreas 2008; 36: 187-191

11 Ito $K$, Horaguchi J, Fujita $N$ et al. Clinical usefulness of double-guidewire technique for difficult biliary cannulation in endoscopic retrograde cholangiopancreatography. Dig Endosc 2014; 26: 442 - 449

12 Testoni PA, Testoni S, Giussani A. Difficult biliary cannulation during ERCP: how to facilitate biliary access and minimize the risk of postERCP pancreatitis. Dig Liver Dis 2011; 43: 596-603

13 Catalano MF, Linder JD, Geenen JE. Endoscopic transpancreatic papillary septotomy for inaccessible obstructed bile ducts: Comparison with standard pre-cut papillotomy. Gastrointest Endosc 2004; 60: 557-561

14 Freeman ML, DiSario JA, Nelson DB et al. Risk factors for post-ERCP pancreatitis: a prospective, multicenter study. Gastrointest Endosc 2001; 54: $425-434$

15 Masci E, Mariani A, Curioni $S$ et al. Risk factors for pancreatitis following endoscopic retrograde cholangiopancreatography: a meta-analysis. Endoscopy 2003; 35: 830-834

16 Sasahira N, Kawakami $\mathrm{H}$, Isayama $\mathrm{H}$ et al. Early use of double-guidewire technique to facilitate selective bile duct cannulation: the multicenter randomized controlled EDUCATION trial. Endoscopy 2015; 47 : $421-429$

17 Lee TH, Hwang SO, Choi HJ et al. Sequential algorithm analysis to facilitate selective biliary access for difficult biliary cannulation in ERCP: a prospective clinical study. BMC Gastroenterol 2014; 14: 30 